\title{
Discharge Coefficient Behaviour in Presence of Four Perforated Plates Flow Conditioners
}

\author{
Laribi Boualem ${ }^{1}$, Abdellah Hadj Abdellah ${ }^{2}$ \\ ${ }^{1}$ University Djillali Bounaama de Khemis Miliana \\ Route de Theniet El Had, Khemis Miliana, Algeria \\ b.laribi@univ-dbkm.dz \\ ${ }^{2}$ University Feres Yahia de Medea \\ LMP2M Laboratory, Medea, Algeria \\ lmp2m_cum@yahoo.fr
}

\begin{abstract}
This paper present a numerical experimentation of the behaviour of the discharge coefficient and the effect of four perforated plates like flow conditioners on the discharge coefficient for flow measurement accuracy. Three of the plates are described by the Standard ISO5167 and the fourth one is proposed for study. The flow is subject to two disturbers namely $50 \%$ closed valve and $90^{\circ}$ double bend in perpendicular planes. The turbulent flow is examined in conduit with an inner diameter of $\mathrm{D}=100 \mathrm{~mm}$. The diameter of orifice meters are respectively $\mathrm{d}=50,60,70$ and $75 \mathrm{~mm}$ which done for $\beta$ ratio $\mathrm{d} / \mathrm{D}$ respectively the values of $0.5,0.6,0.7$ and 0.75 . The orifice meters are located in conduit at different stations z/D downstream the disturbers. The flow is examined with air at Reynolds number $\operatorname{Re}=2.5 \times 10^{5}$. The results showed that the perforated plates have significantly reduced the error on the discharge coefficient. Indeed, the errors recorded downstream disturbers are superior to $12 \%$. Downstream the perforated plates used separately the errors on the discharge coefficient are reduced to a value inferior to $1 \%$ for the four plates. It is noted that the standards ISO5167 and AGA3 stipulate that the error on the discharge coefficient $\mathrm{Cd}$ must be less than $0.5 \%$ for better flow measurement accuracy. By comparing our results with this condition we found that the error obtained on the discharge coefficient with the four perforated plates are substantially reduced especially downstream station $z=25 \mathrm{D}(\mathrm{z}=19 \mathrm{D}$ downstream disturbers). However the fourth proposed plate with its height porosity produces less lose pressure than those of the other three plates. This is good conditions of exploitation for some installation where height lose pressure are not tolerated.
\end{abstract}

Keywords: Perforated plates flow conditioners, flowmetring, discharge coefficient.

\section{Introduction}

The majority of the orifice meters must be calibrated. This is done in fully developed pipe flow, axisymmetric pipe that is free from swirl and pulsation. Standards such as ISO5167 [1] define a satisfactory flow. While high accuracy about $0.5 \%$ flow rate measurement is required, disturbances in the flow caused by valves, bends, and other component introduce errors of more than $3 \%$.

Given that most industrial installations include disturbers like bends, valves, expanders and reducers, which are sources of swirl, asymmetries and turbulence distortions, insuring that fully developed flow in terms of mean flow and turbulence structure approach the meter is difficult to achieve in practical situations.

For best accuracy, a flow meter needs to be presented with an axisymmetric, fully developed velocity profile with zero swirls. Either very long lengths of straight pipe work upstream of the flow meter must be provided as recommended by standards ISO 5167 and AGA-3 [2], these may need to be of the order of 80 to 100 pipe diameters, which will give a higher installation cost and greater space requirement.

Research work by Gallagher J. [2], T.T. Yeh and G. Mattingly [3], Laribi B. and al [4-7], R. Rans [8], Darin L. and Bowles E. B. [9], F. Sharipov [10] and more recently Laribi B. and al [11] have reported a number of computational studies of installation effects on orifice meter performances.

Our paper examines the effect of for perforated plates with orifice meters on the shift deviation of the discharge coefficient for best metrological performances basing on the pressure drop across the orifice in non-standard conditions. 
The investigation is conducted to show the effect of the two disturbers namely a $90^{\circ}$ double bends in perpendicular planes and a $50 \%$ closed valve on the deviation of the discharge coefficient.

\section{Turbulence Models}

The general equation used in CFD code is given by Eq. 1 as bellow:

$$
\frac{\partial}{\partial t}(\rho \phi)+\nabla U \phi=\nabla\left(\Gamma_{\phi} g r a d \phi\right)+S_{\phi}
$$

Where:

$\phi$ a general variable which can be velocity $\mathrm{U}\left(\mathrm{m} \cdot \mathrm{s}^{-1}\right)$, turbulence kinetic energy $\mathrm{k}\left(\mathrm{kg} \cdot \mathrm{m}^{-2} \cdot \mathrm{s}^{-2}\right)$ or the dissipation rate $\varepsilon\left(\mathrm{m}^{-2} \cdot \mathrm{s}^{-3}\right)$.

$\rho$ is the density of fluid $\left(\mathrm{kg} \cdot \mathrm{m}^{-3}\right)$.

$\Gamma_{\phi}$ is the diffusion coefficient of the variable $\phi$.

$\mathrm{S}_{\phi}$ is the source term of the variable $\phi$.

The turbulence model used for this simulation is $\mathrm{k}-\varepsilon$ model. It is the simplest and complete model known as two equations. This model assumes that the turbulent regime is fully established throughout the area and that the effects of molecular viscosity are negligible compared to the turbulent viscosity (away from walls). It is based on the Boussinesq hypothesis. It is a semi-empirical model. Two transport equations are used, one for the turbulence kinetic energy k and the other for its dissipation rate $\varepsilon$. The reader can consult the literature Fluent [12] for thorough study.

\section{Experimental Facility for the Simulation}

\subsection{Air Flow Rig}

The basic experimental facility is presented in figure 1. It consists of a long conduit pipe with $100 \mathrm{~mm}$ inner diameter. The air enters the pipe then flows through a straight pipe of $10 \mathrm{D}$ length, which is followed by disturbers. The $90^{\circ}$ double bend in perpendicular planes and 50\% closed valve were used separately. The orifice meter diameters used in this simulation are respectively $d=50,60,70$ and $75 \mathrm{~mm}$ diameters which done for $\beta$ ratio $\mathrm{d} / \mathrm{D}$ respectively the values of 0.5 , 0.6, 0.7 and 0.75 . The first orifice meter is installed at 97D downstream of the flow disturber, where the flow is fully developed. Stations used for the second orifice meters are respectively $1.5 \mathrm{D}, 7 \mathrm{D}, 12 \mathrm{D}, 17.5 \mathrm{D}, 25 \mathrm{D}, 35 \mathrm{D}$ downstream the disturber.

The two orifice meters have standard geometry. A length of 10D is provided downstream the entrance of flow and downstream the orifice meter installed at station 91D for natural flow development. The Reynolds number of the turbulent flow is $2.5 \times 10^{5}$.

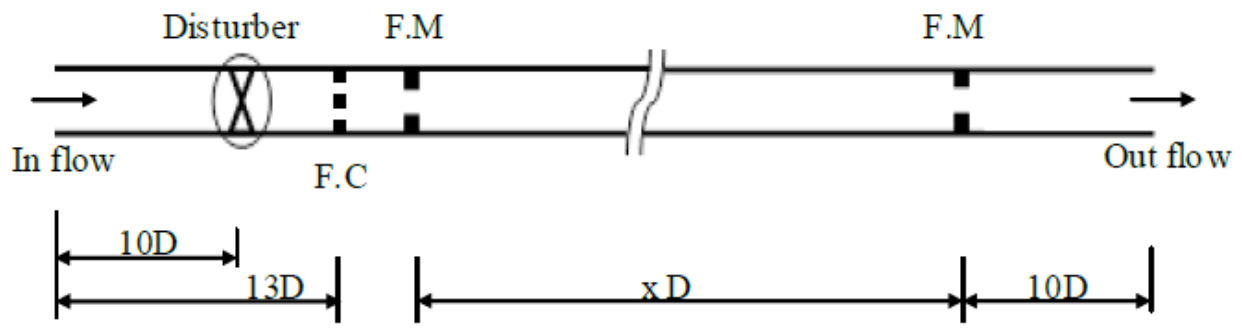

Fig. 1: Conduit.

\subsection{Perforated Plates used in simulation}

The three perforated plates flow conditioners (F.C.) used in the study and described by the Standard ISO5167 are shown in figure 2 . The forth one is our proposed plate. 


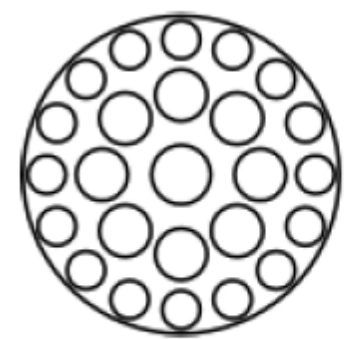

NOVA F.C. (P1)

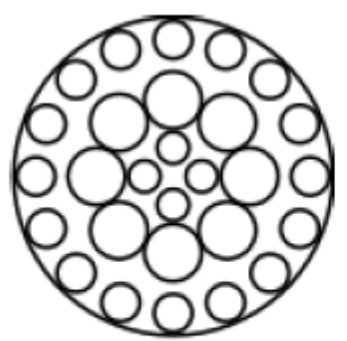

NEL F.C. (P2)

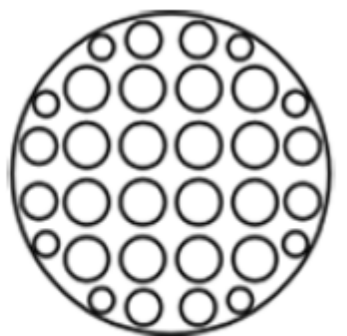

ZANKER F.C. (P3)

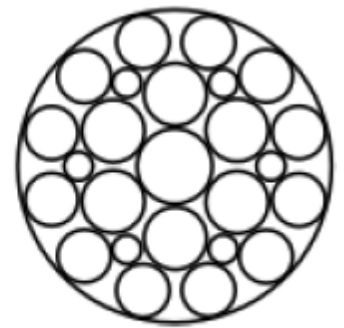

NEW Plate (P4)

Fig. 2: The four perforated plates.

\subsection{Variation of the Discharge Coefficient}

For testing the effect of disturbers on the discharge coefficients of the orifice meters, the shift deviation for the discharge coefficient $\Delta \mathrm{Cd}(\%)$ is calculated by using the difference pressure $\square \mathrm{P}$ obtained by the simulation at different locations of the orifice meter in the pipe and $\square \mathrm{Po}$ at the same time at station z/D=97 were the flow is fully developed. Eq. 2 shows the calculus formula:

$$
\Delta \mathrm{Cd}(\%)=\sqrt{\frac{\Delta \mathrm{Po}}{\Delta \mathrm{P}}}-1
$$

The difference pressure is calculated according to the standard ISO 5167 at D upstream and D/2 downstream the orifice meter. This formula was applied for the four orifice plates with the two disturbers.

\section{Results and Discussion}

\subsection{Discharge Coefficient Errors with $50 \%$ Closed Valve on Line and Perforated Plates}

Experiments were conducted to determine the relative change in the orifice meter discharge coefficient when subjected to non-standard approaching flow conditions like 50\% closed valve. The test sections were 1.5D, 7D, 12D, 17.5D, 25D, $35 \mathrm{D}$ downstream the valve. The effect of valve on the orifice meter with the four orifice meters with $\beta=0.50,0.60,0.70$ and 0.75 respectively at Reynolds number of $2.5 \times 10^{5}$ is shown in figure 3 . The principal remark shown in this figure is that at station $\mathrm{z} / \mathrm{D}=1.5$ when $\beta$ increases, $\Delta \mathrm{Cd}(\%)$ increases. This situation is the same in presence of the four perforated plates used in this numerical study.

Indeed, we register at station $\mathrm{z} / \mathrm{D}=7$ a value close to zero for $\Delta \mathrm{Cd}(\%)$ with $\beta=0.5$ with the NOVA F.C. This value increases to reach a mean value more than $3 \%$ for $\beta=0.75$ with the other flow conditioners. We have to remember that the Standard ISO 5167 recommend a maximum value for $\Delta \mathrm{Cd}(\%)$ of $0.5 \%$. Our results are in good agreement with the standard for station $\mathrm{z} / \mathrm{D}=17.5$ and more for the four flow conditioners. This result let's suppose that if we would like to get a good flow measurement, the orifice meter must be placed at station $\mathrm{z} / \mathrm{D}=25$ or more downstream the valve. 

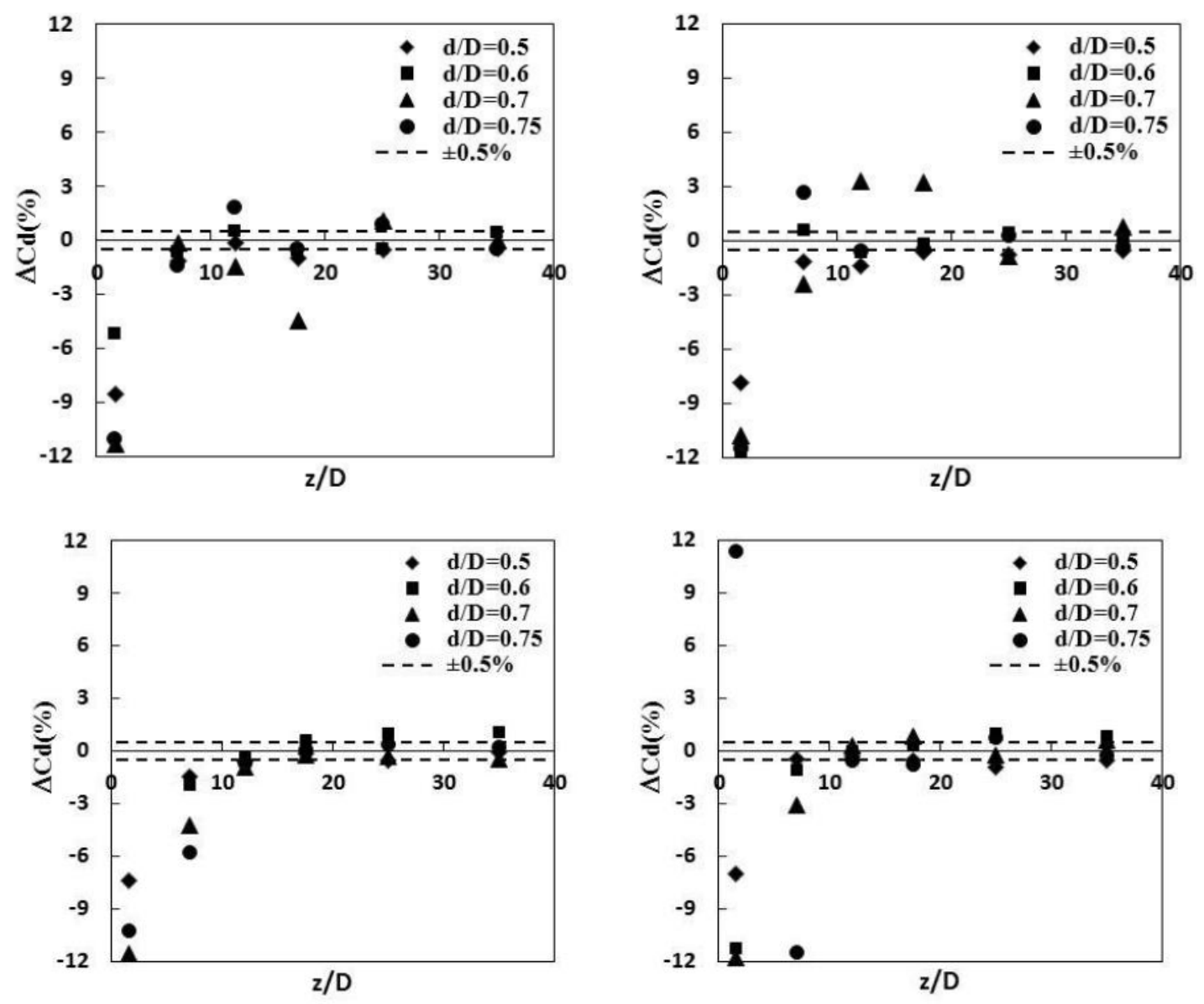

ZANKER F.C. (P3)

NEW Plate (P4)

Fig. 3: Discharge coefficient errors for the four F. C. with valve $50 \%$ closed.

\subsection{Discharge Coefficient Errors with Double Bend on Line}

In this case, experiments were conducted to determine the relative change in the orifice meter discharge coefficient when subjected to $90^{\circ}$ double bend in perpendicular planes. The test sections were $1.5 \mathrm{D}, 7 \mathrm{D}, 12 \mathrm{D}, 17.5 \mathrm{D}, 25 \mathrm{D}, 35 \mathrm{D}$ downstream the double bend. The effect of this disturbers on the orifice meter with the four orifice meters with $\beta=0.50$, $0.60,0.70$ and 0.75 respectively with a Reynolds number of $2.5 \times 10^{5}$ is shown in figure 4 . The principal remark shown in this figure is the same which obtained with the valve. Indeed, when $\beta$ increases, $\Delta \mathrm{Cd}(\%)$ increases especially at station $\mathrm{z} / \mathrm{D}=7$. This situation is the same for the four perforated plates used in this study. We register at station $\mathrm{z} / \mathrm{D}=7$ a value close to $0.3 \%$ for $\Delta \mathrm{Cd}(\%)$ with $\beta=0.5$ with NOVA F.C. and reach a mean value $2.7 \%$ for $\beta=0.75$ for the NEL F.C. Our results are in good agreement with the standard for station $\mathrm{z} / \mathrm{D}=25$ and more. This result is the same of results obtained for the valve. 

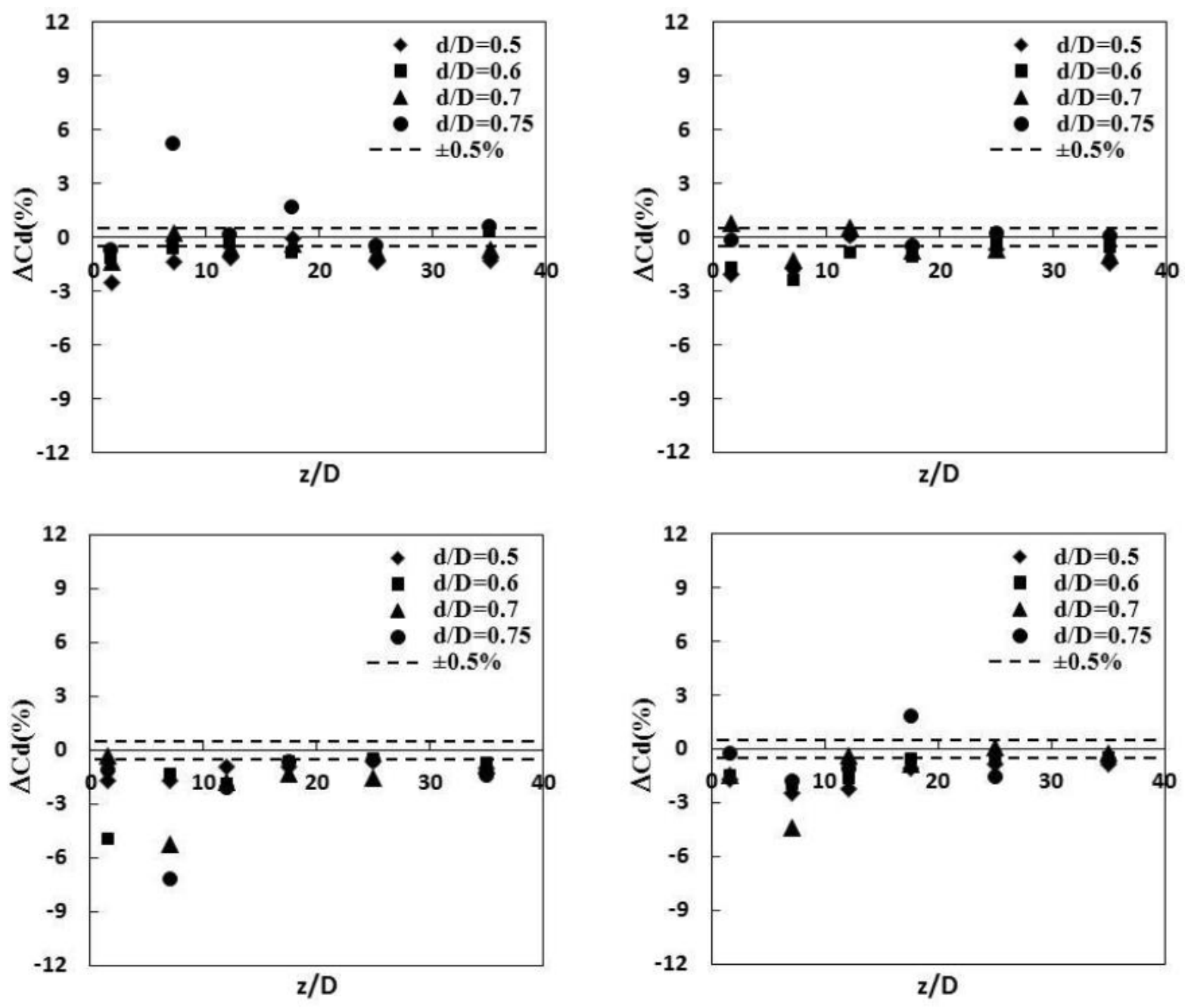

ZANKER F.C. (P3)

NEW Plate (P4)

Fig. 4: Discharge coefficient errors with double bend 90o on line.

\section{Conclusion}

The present numerical investigation examines the effect of upstream conditions on orifice meters otherwise on the discharge coefficient $\mathrm{Cd}$. The flow is disturbed by a $50 \%$ closed valve and a $90^{\circ}$ double bend in perpendicular planes used separately. The discharge coefficient were measured with four different orifice meters with $\beta=0.5,0.6,0.70$ and 0.75 at Reynolds number $\mathrm{Re}=2.5 \times 10^{5}$.

The principal result shows that when $\beta$ increases the shift deviation on the discharge coefficient $\Delta \mathrm{Cd}(\%)$ increases. This result is the same with the two disturbers. Indeed if we would like to get a good flow measurement, the flow meter must be located at distance $\mathrm{z} / \mathrm{D}=25$ downstream the disturber or more. In this situation, a good agreement is obtained with the standards ISO 5167.

We also concluded that the valve $50 \%$ closed could be considered for further experimental investigations than the $90 \square$ double bend in perpendicular planes which gave minimum errors (minimum disturbances) on the discharge coefficient contrary to the valve.

At last, the CFD shows their efficiency to predict the flow behaviour in different situations and let us to plain our experimental study in optimal conditions in order to validate the numerical investigations. 


\section{Acknowledgements}

This study is a part of a research project approved by the Algerian Ministry of Higher Education and Scientific Research under number J0303920130026. The authors acknowledge the High Ministry of Education and Scientific Research of Algeria for supporting financially this project.

\section{References}

[1] ISO 5167, 2003, "Measurement of fluid flow by means of orifice plates nozzles and ventury tubes inserted in circular cross section conduits running fuel," [Online]. Available: http://www.iso.org/iso/

[2] AGA-3, 1980, "Orifice Metering of Natural Gas and the Related Hydrocarbone Fuels," [Online]. Available: http://www.aga.org

[3] T. T. Yeh and G. Mattingly, 1996. E, "Flow meter installation effects due to a generic header". NIST Technical note 1419. [Online]. Available: http://catalogue.nla.gov.au/

[4] B. Laribi, P. Wauters and M. Aichouni, "Experimental Study of the Decay of Swirling Turbulent Pipe Flow and its Effect on Orifice Flow Meter Performance," ASME Fluids Engineering Division Summer Meeting, FEDSM'01, 2001.

[5] B. Laribi, P. Wauters and M. Aichouni, "Comparative study of aerodynamic behaviour of three flow conditioners," European Journal of Mechanical and Environmental Engineering, vol. 48, no. 1, pp. 21-30, 2003.

[6] B. Laribi, et al, "Numerical investigation of contribution of three flow conditioners in the development and establishment of turbulent flows," in Proceedings of ASME 2010 3rd joint USEuropean Fluids Engineering Summer Meeting, and 8th International Conference on Nanochannels, Microchannels and Minichannels, FEDSM2010ICNMM2010, Canada, 2010.

[7] B. Laribi and al, "Numerical investigation of turbulent models in the development and establishment of turbulent flows with flow conditioners," in Proceedings of ASME 2010 3rd joint US-European Fluids Engineering Summer Meeting, and 8th International Conference on Nanochannels, Microchannels and Minichannels, FEDSM2010ICNMM2010, Montreal, Canada, 2010.

[8] R. Rans, et al, "Flow Conditioning and Effects on Accuracy for Fluid measurement," 7th East Asia Hydrocarbon Flow Measurement Workshop 5th - 7th, Malaysia, 2008.

[9] L. Darin \& E. B. Bowles, "Conditioning on Gas Measurement," Pipeline \& Gas Journal, pp. 59-62, 2008.

[10] F. Sharipov, "Numerical simulation of rarefied gas flow through a thin orifice," J. of Fluids Mechanics, vol. 518, pp. 35-60, 2004.

[11] B. Laribi and A. Ait-Amrane, "Numerical analysis of the discharge coefficient with disturbers for flowmetring accuracy on flow measurement," 16th International Metrology Congress - Paris, 2013.

[12] Fluent v6.3, Fluent incorporated, Journal Centerra source park, USA, 2006. 